\title{
Original article \\ Moisture sorption isotherms and isosteric heat of sorption of coffee in different processing levels
}

\author{
Paulo C. Corrêa, André L. D. Goneli, Paulo C. A. Júnior, Gabriel H. H. de Oliveira ${ }^{1} *$ \& Domingos S. M. Valente \\ Department of Agricultural Engineering, Federal University of Viçosa, Campus UFV s/n, PO Box 370, 36570-000, Viçosa - MG, Brazil
}

(Received 16 March 2010; Accepted in revised form 24 June 2010)

Summary The desorption isotherms and thermodynamic properties of coffee from different processing stages were obtained during the drying process of this product. The isotherms were determined by a static gravimetric method for various temperature and humidity conditions. Equilibrium moisture content $\left(M_{\mathrm{e}}\right)$ data were correlated by several mathematical models and an artificial neural network (ANN) model. The $\mathrm{M}_{\mathrm{e}}$ for coffee fruits, pulped coffee and green coffee increased with an increase in the water activity $\left(a_{\mathrm{w}}\right)$ at any particular temperature. At a constant $a_{\mathrm{w}}$, coffee fruits samples had higher $M_{\mathrm{e}}$ than the remaining coffee samples. Based on statistical parameters, the ANN model, modified Henderson and GAB models were adequate to describe the sorption characteristics of the samples. Isosteric heat of sorption was evaluated by means of the Clausius-Clapeyron equation. It decreased with increasing moisture content. The coffee fruits had higher isosteric heat of sorption than that pulped coffee and green coffee.

Keywords Artificial neural network model, Coffea arabica L, equilibrium moisture content, isosteric heat, mathematical modelling.

\section{Introduction}

Coffee is considered one of the most important products in Brazil and in the world, because of the income from exportation and industrialisation and the number of direct and indirect employments related to this commodity. Brazil is the world's leader producer of coffee, with a production of two million tons of grains in 2007 (FAO, 2008). To consolidate its economic success and sustainability, a technological model of production is crucial to improve its quality.

Such as several agricultural products, coffee presents high moisture content when harvested. Losses caused by excessive moisture and high sugar content in the coffee pulp may be intensified if postharvest techniques are not applied in the most efficient manner (Quintero, 1999). Coffee can be processed in two different ways: "dry method' or integral form and 'wet method' or hulling. In the dry process, coffee fruits are used in its natural form (peeled) and stages of the processes involves deficiency of water, originating coffee fruit dried on yards or dried cherry. Through wet process, which originates pulped

\footnotetext{
*Correspondence: Fax: + 55313891 1943;

e-mail: gabriel.oliveira@ufv.br

${ }^{1}$ The present work was carried out in the Laboratory of Physical Properties and Quality Evaluation of Agricultural Products at the National Grain Storage Training Center - CENTREINAR, Federal University of Viçosa, Viçosa, MG, Brazil.
}

coffee, it requires the use of water, being the grains submitted to the process without their hulls. The hulls can be removed containing the sugary mucilage which involves the coffee beans. This mucilage facilitates the microorganism's activity, responsible for quality reduction (Barel \& Jacquet, 1994).

The behaviour of coffee beans is similar to different agricultural products, which are capable of relish or absorb water from the surroundings, known as hygroscopicity. To guarantee the high final quality of the product, it is important to store coffee in dry places with low moisture content. The contrary would increase the incidence of microorganisms that cause undesirable fermentations and toxin contamination, depreciating the products' quality and commercialisation. In the other hand, the reduction in moisture content promotes economical losses because of mass loss (Yazdani et al., 2006).

To correctly conduct drying and storage operations, it is necessary to know the relationship between air temperature (T) and relative humidity $(\mathrm{RH})$, and desirable conditions for preserving the product. To obtain this information, sorption isotherms are indispensable. These are developed through the relationship between equilibrium moisture content $\left(M_{\mathrm{e}}\right)$ and equilibrium relative humidity or water activity $\left(a_{\mathrm{w}}\right)$, being expressed by mathematical models. Researchers have studied hygroscopic behaviour of several agricultural products, describing differentiated models to express the 
$M_{\mathrm{e}}$ as a function of the temperature and water activity (Pagano \& Mascheroni, 2005; Chowdhury et al., 2006; Corrêa et al., 2007; Iguaz \& Vírseda, 2007). There are over 200 models proposed in literature to represent hygroscopic equilibrium of agricultural models. These models differ in their theoretical or empirical basis and in the number of parameters involved (Mulet et al., 2002). The description of sorption isotherms of agricultural products can be made by more than one model of $M_{\mathrm{e}}$. The main criteria to select models are the adjustment degree to experimental data and how simple the model is (Furmaniak et al., 2007). Burmester \& Eggers (2010) acquired the sorption isotherms of coffee beans without parchment; however, information regarding coffee isotherms during the wet processing was not found in the literature.

Recently, a different approach to model the drying of foodstuffs has been used. Artificial neural networks $(\mathrm{ANN})$ is a different method to calculate and predict moisture content of agricultural products at certain environment conditions and have the advantage to provide a single model for different products and cultivars. According to Lertworasirikul \& Tipsuwan (2008), ANN do not involve parameters of physical models, have the ability to learn from experimental data and are capable of handling complex systems with nonlinearities and interactions between decision variables. On the other hand, using this modelling procedure leads to a loss of knowledge of the food properties during drying, which can be evaluated by means of the parameters of the mathematical models. Recent studies have been using ANN for modelling drying (Bala et al., 2005; Movagharnejad \& Nikzad, 2007; Poonnoy et al., 2007; Lertworasirikul \& Tipsuwan, 2008) and sorption isotherms (Panchariya et al., 2002; Peng et al., 2007; Janjai et al., 2009; Oliveira et al., 2010).

Thermodynamic parameters, such as isosteric heat, are frequently evaluated from $M_{\mathrm{e}}$ data at different temperatures (Iglesias \& Chirife, 1976a). Thermodynamic principles are applied in sorption isotherm data to obtain more information about energy requirement of dehydration, properties of water, food microstructure, physical phenomena on food surfaces and sorption kinetic parameters. One method widely used for calculating isosteric heat of sorption is based on the ClausiusClapeyron equation, which assumes temperature-independent heat of sorption and allows easy calculation of isosteric heat from sorption isotherms (Aguerre et al., 1988).

In view of the importance of understanding the hygroscopicity of agricultural products, this work aimed to determine and model the sorption isotherms of green coffee, pulped coffee and coffee fruit for various temperature and relative humidity conditions; to fit several mathematical models to the experimental data; and to calculate the isosteric heat of sorption at different moisture levels. In addition, an ANN model was fitted to the experimental data of the different processing coffee to predict the equilibrium isotherms in a single model.

\section{Materials and methods}

The present work was conducted in the Laboratory of Evaluation of Physical Properties and Quality of Agricultural Products from the National Grain Storage Training Center - CENTREINAR, Federal University of Viçosa, Viçosa, MG, Brazil.

Coffee fruits (Coffea arabica L), variety 'Catuai Vermelho', were manually harvested during cherry stage. During harvest, unripened, deteriorated and injured coffee beans were eliminated. After harvested, fruits were washed and selected for the better characterisation of the material. To obtain different means of processing coffee, part of coffee fruits was hulled (pulped coffee), while the rest was retrieved directly from the washer (green coffee). Figure S1 shows a flow chart of the wet processing of coffee.

Owing to the high initial moisture content and the risks associated with this trend (microorganism's development, plague attack), coffee fruits and pulped coffee were submitted to partial drying on cement yards. They were dried until moisture content of $45 \%$ dry basis (d.b.). For green coffee tests, samples were partially dried until approximately $31 \%$ d.b. of moisture content using an air conditioner unity manufactured Aminco, model Aminco-Aire 150/300 applying low temperature drying $\left(40{ }^{\circ} \mathrm{C}\right)$ and relative humidity about $60 \%$, with airflow of $10 \mathrm{~m}^{3}$ per $\mathrm{min}^{-1} \mathrm{~m}^{-2}$. At the end of drying process, the material had its parchment and silver pellicle (which involves coffee pulped) manually removed, afterwards been submitted to analyses.

Two samples were stored in polythene bags kept in a refrigerator to attain moisture uniformity. When required, samples were left in room conditions for $6 \mathrm{~h}$ to achieve moisture equilibrium. According to Seeds Analysis Standard of Brazil (Brazil, 1992), moisture content of coffee fruits, pulped coffee and green coffee was determined by applying the oven method at $105 \pm 1{ }^{\circ} \mathrm{C}$ for $24 \mathrm{~h}$, in duplicate.

\section{Sorption isotherms determination}

Equilibrium moisture content $\left(M_{\mathrm{e}}\right)$ of green, pulped and coffee fruits was determined using the static method, which is based on the use of saturated salt solutions to maintain constant water activity of samples once equilibrium between room conditions and food sample is reached. Salt solutions used were $\mathrm{NH}_{4} \mathrm{Cl}, \mathrm{KBr}, \mathrm{KNO}_{2}, \mathrm{KNO}_{3}, \mathrm{~K}_{2} \mathrm{SO}_{4}, \mathrm{CaCl}_{2}, \mathrm{Ca}\left(\mathrm{NO}_{3}\right)_{2}$, 
$\mathrm{Na}_{2} \mathrm{Cr}_{2} \mathrm{O}_{7}, \mathrm{MgCl}_{2} \cdot 6 \mathrm{H}_{2} \mathrm{O}, \mathrm{LiCl}, \mathrm{LiCl} . \mathrm{H}_{2} \mathrm{O}$ and $\mathrm{NaCl}$. This group of salts provides a wide range of relative humidity, ranging from $11 \%$ to $95 \%$. To determine sorption isotherms of green coffee, pulped coffee and coffee fruits, the analysis was conducted at the temperature range from 10 to $50^{\circ} \mathrm{C}$. Water activity was measured at five different temperatures: 10, 20, 30, 40 and $50{ }^{\circ} \mathrm{C}$.

To obtain data in order to construct the sorption curves, three samples containing $100 \mathrm{~g}$ of coffee beans at each experimental condition (processing levels and combinations of temperature and water activity) were left in room conditions until static equilibrium was attained. For this purpose, samples were kept in small baskets inside a glass container of $2.0 \mathrm{~L}$ with $250 \mathrm{~mL}$ of salt solutions, hermetically closed and kept in five climacteric boxes with controlled temperature. Baskets were daily weighted until mass variation was lower than $0.001 \mathrm{~g}$. Subsequently, the moisture contents of these samples were determined, obtaining the equilibrium moisture content for each treatment condition.

\section{Data analyses}

Several theoretical (BET, GAB model, etc.) and empirical equations (Chung Pfost, Modified Oswin, Modified Henderson, etc.) are available for the modelling of sorption isotherms data. In this study, the relationship between equilibrium moisture content and the environment conditions of coffee fruits, pulped coffee and green coffee was modelled using the models presented in Table S1.

An independent multilayer ANN model for $M_{\mathrm{e}}$ prediction of coffee was proposed. The model has a five-layered network of neurons with a 3-3-5-3-1 configuration, as presented in Fig. S2. The input layer of the model consists of three neurons corresponding to the three input variables (temperature, relative humidity and type of coffee), while the output layer has one neuron, which represents the $M_{\mathrm{e}}$ in the model. The ANN drier models were trained by backpropagation algorithm method. The ANN model was programmed in MATLAB version 6.5 (Francisco de Assis de Carvalho Pinto, Viçosa-MG, Brazil). The transfer functions used at the ANN were logarithmic sigmoid for the first and second layers, tangent hyperbolic for the third layer and linear for the output layer. The function utilised in the ANN modelling using the MATLAB software is net = newff (vetor, $[3,5,3,1]$, \{'logsig', 'logsig','tansig','purelin'\},'trainlm'). The model of equilibrium moisture content calculated through ANN was $\mathrm{Me}=\mathrm{fn}($ weight*neuron + bias).

Experimental data were interpreted by means of nonlinear regression analysis adopting the QuasiNewton method, using the software STATISTICA $8.0^{\circledR}$ (Federal University of Viçosa, Viçosa-MG, Brazil).
Models were selected based on the significance of regression coefficients of the ' $t$ ' test, at $1 \%$ of probability. The mean relative per cent deviation $(\mathrm{P})$, standard error of estimate (SE), determination coefficient $\left(R^{2}\right)$ and residual distributions plots were used to evaluate the models' good fit. Mean relative per cent deviation lower than $10 \%$ is considered as one of the criteria for selecting models, according to Mohapatra \& Rao (2005). The mean relative per cent deviation and the standard error were calculated by Equations 1 and 2, respectively.

$$
\begin{gathered}
P=\frac{100}{n} \sum_{i=1}^{n}\left(\frac{\left|M_{\text {exp }}-M_{\text {pre }}\right|}{M_{\text {exp }}}\right) \\
S E=\sqrt{\frac{\sum_{i=1}^{n}\left(M_{\text {exp }}-M_{\text {pre }}\right)^{2}}{D F}}
\end{gathered}
$$

In which, $\mathrm{P}$ is the mean relative per cent deviation $(\%) ; \mathrm{n}$ is the number of observed data; $M_{\exp }$ is the experimental value of equilibrium moisture content, $\%$ d.b.; $M_{\text {pre }}$ is the predicted value of equilibrium moisture content through the model, \% d.b.; SE is the standard error of estimate, \% d.b.; DF is the degrees of freedom of the model.

Residuals were plotted against $M_{\text {pre }}$ values. A model is considered acceptable if residual values are in a horizontal band centred around zero, displaying no systematic tendencies (i.e. random in nature) towards a clear pattern. If the residual plot indicates clear pattern, the model is considered unacceptable.

\section{Determination of isosteric heat of sorption}

Net isosteric heat of sorption was determined from moisture sorption data using the following equation, derived from the Clausius-Clapeyron equation (Iglesias \& Chirife, 1976a):

$$
\frac{\partial \ln \left(a_{\mathrm{w}}\right)}{\partial T_{\mathrm{k}}}=\frac{q_{\mathrm{st}}}{R T_{\mathrm{k}}^{2}}
$$

In which, $a_{\mathrm{w}}$ is water activity, decimal; $T_{\mathrm{k}}$ is absolute temperature, $K ; q_{\mathrm{st}}$ is the net isosteric heat of sorption, $\mathrm{kJ} \mathrm{kg}^{-1} ; R$ is the universal gas constant, $\mathrm{kJ} \mathrm{kg}^{-1} \mathrm{k}^{-1}$.

Integrating Equation 3, assuming that $\mathrm{q}_{\mathrm{st}}$ is independent of temperature, gives the following equation (Wang \& Brennan, 1991):

$$
\ln \left(a_{w}\right)=-\left(\frac{q_{s t}}{R}\right) \frac{1}{T_{k}}+K
$$

In which, $\mathrm{K}$ is a constant.

The sorption isosteric heat $\left(Q_{\mathrm{st}}\right)$ can be calculated by adding the latent heat of vaporisation for pure water (L) to the $q_{\mathrm{st}}$ (Sanchez et al., 1997): 


$$
Q_{\mathrm{st}}=q_{\mathrm{st}}+L=a \exp \left(-b M_{\mathrm{e}}\right)+L
$$

In which, $Q_{\mathrm{st}}$ is the sorption isosteric heat, $\mathrm{kJ} \mathrm{kg}^{-1}$; $\mathrm{L}$ is the latent heat of vaporisation of pure water, $\mathrm{kJ} \mathrm{kg}^{-1}$; $\mathrm{a}$ and $\mathrm{b}$ are constants; $M_{\mathrm{e}}$ is the equilibrium moisture content, $\%$ d.b.

\section{Results and discussion}

\section{Sorption isotherms modelling}

The results from the mathematical modelling of the experimental data of green, pulped and coffee fruits using the equations from Table $\mathrm{S} 1$ are presented in Tables S2, S3 and S4, respectively.

The mathematical models tested to estimate equilibrium moisture content of green coffee presented values of determination coefficient $\left(R^{2}\right)$ above $97 \%$ (Table S2) and low SE values. According to Aviara et al. (2004), the $R^{2}$ and $\mathrm{SE}$ values are not sufficient to prove adjustment quality of a hygroscopic equilibrium model to the experimental data of equilibrium moisture content, because with these statistical parameters, the distribution tendency of residual values is evaluated. Graphing of the resulting residual values from the tested models revealed that all models with the exception of the modified Halsey model presented random distribution tendency of residual values, indicating more suitable adjustment to the hygroscopicity phenomenon.

Observing Table S2, the modified Halsey and modified Oswin models presented $P$ values above $10 \%$, being inadequate to describe the equilibrium moisture content (Özdemir \& Devres, 1999). Therefore, Copace, ChungPfost, modified Henderson and modified GAB models presented a better fitting to the experimental data of equilibrium moisture content of green coffee. Thus, the application of these models is recommended to estimate the equilibrium moisture content of green coffee. Also, Iguaz \& Vírseda (2007) obtained a good fit to the experimental data of equilibrium moisture content of rough rice with the modified Henderson, modified Chung-Pfost and modified GAB models, the last adjusting the best among all models.

Regarding the pulped coffee, estimated coefficients for models showed $R^{2}$ above $96 \%$ (Table S3). Likewise for green coffee, the modified Halsey was the only model that presented a pattern distribution of the residuals. The remaining models obtained $\mathrm{P}$ values lower than $10 \%$ and random distributions; therefore, they can be considered adequate for describing experimental sorption data for pulped coffee. These results match with those found by Corrêa et al. (2007), working with peanut pods.

All models presented values of $R^{2}$ above $97 \%$ and mean relative error below $10 \%$ for coffee fruits
(Table S4). Such as the remaining processing coffee, the modified Halsey model showed to be inadequate for describing the equilibrium moisture content, with the residual plot indicating clear pattern. According to Giner \& Gely (2005), modified Halsey permits better representation of sorption isotherms of oilseeds, because it reproduces the sharp increase in moisture content at high water activity. This fact is not observed in coffee and its processing procedures.

The modelling procedure consists to obtain a model that is suitable to predict the experimental data and possess the fewer parameter number, being easier to work with. In addition, according to Draper \& Smith (1998), the capacity of the model to faithfully describe a certain physical process is inversely proportional to the SE values. Also, the modified Henderson model has been widely used by engineers to predict and it is recommended by the American Society of Agricultural and Biological Engineers (ASABE) owing to its easier comprehension. Being that stated, the modified Henderson model was chosen to represent the sorption experimental data of green coffee, coffee pulped and coffee fruit.

Being that concluded and with the purpose to enlighten the modelling procedure, Fig. S3 presents the residual plot of modified Henderson model, an example of a residual plot with random distribution.

Figure $\mathrm{S} 4$ shows the moisture sorption isotherms of green, pulped and coffee fruit obtained at $10^{\circ} \mathrm{C}$ calculated through the modified Henderson model to illustrate the moisture behaviour, similar to the remaining temperatures. The equilibrium moisture content at each water activity represents the mean value of three replications. As expected, the equilibrium moisture content increased as water activity increased at any particular temperature and decreased as temperature increased at constant water activity. This indicates that coffee, in its different preparation procedures, becomes less hygroscopic as temperature increases.

Temperature increase activates water molecules to higher energy levels, allowing them to break away from their sorption sites, therefore decreasing the equilibrium moisture content (Palipane \& Driscoll, 1992). As temperature vary, the excitation of molecules, as well as the distance, and thus attraction between molecules, varies. This causes the amount of sorbed water to change as temperature varies, at a given relative humidity (Mohsenin, 1986). Mazza \& Lemaguer (1980) suggested that an increase in temperature induces physical and/or chemical changes in the product, which reduces the number of active sites for water to bind. Temperature dependence on equilibrium moisture content has an important practical bearing on chemical and microbiological reactions associated with spoilage (Al-Muhtaseb et al., 2004). Temperature increase leads to water activity increase, at the same moisture content, which 
in turn causes an increase in the reaction rates, leading to quality deterioration (Van den Berg \& Bruin, 1981).

Sorption isotherms of samples of green coffee, pulped coffee and coffee fruit showed type II behaviour according to the BET classification (Brunauer et al., 1940). At a constant water activity, samples of coffee fruits had higher equilibrium moisture content than pulped and green coffee samples, indicating higher hygroscopicity of the product. This might be attributed to the separation of hulls from parchment coffee (pulped coffee), as hulled process reduces fibre content, which absorbs more water. These results agree with those found by Kaya \& Kahyaoglu (2006) who evaluated the influence of dehulling and roasting process on the thermodynamics of moisture adsorption in sesame seed. Corrêa et al. (2007) reported that peanut hulls have higher hygroscopicity than peanut pods and kernels. For the range of temperature under study, sorption isotherms of pulped and green coffee had similar values. These results are probably due to the low hygroscopicity of the layer which involved pulped coffee, the parchment, basically made of cellulose, hemicelluloses and lignin (Wilbaux, 1961).

The ANN model of the equilibrium moisture content of coffee of different processing procedures was developed by training it with experimental desorption data. Sorption data were randomly separated, and $25 \%$ of this data were used to train the ANN model; in other words, 20 pairs of temperature and relative humidity data for each type of coffee, totalising 60 data (three types of coffee), being that 15 pairs $(25 \%)$ were used to acquire the ANN model. Weight and bias of each neuron and layers are presented in Table S5.

The analysis of the suitability of the ANN model is obtained through the comparison between the modelpredicted and measured equilibrium moisture contents of coffee shown in Fig. S5. From this figure, it can be observed that the agreement between the predicted and observed $\mathrm{M}_{\mathrm{e}}$ is excellent $\left(R^{2}=99.25 \%\right)$. Furthermore, values of $\mathrm{P}$ and $\mathrm{SE}$ of the ANN model were $5.31 \%$ and $0.51 \%$ d.b., respectively. Thus, either of the ANN or modified Henderson models can be used in the prediction of the $M_{\mathrm{e}}$ of coffee.

\section{Isosteric heat of sorption}

The interaction between water vapour and the adsorbent food material should be determined to define the temperature effect, characterised by isosteric heat of sorption $\left(Q_{\mathrm{st}}\right)$ values. At constant moisture content, water activity of equilibrium at each studied temperature was determined using modified Henderson model (because it fitted the experimental data satisfactorily). Values of isosteric heat of sorption were calculated, by applying Equations (4) and (5), and represented with respect to equilibrium moisture content (Fig. S6).
According to Fig. S6, the isosteric heat of sorption decreases continuously as equilibrium moisture content increases for green, pulped coffee and coffee fruit. This fact may be explained based on the assumption that sorption occurs at low moisture contents on the most active sites, hydrophilic groups. As moisture content increases, fewer active sites are available to the water molecules to bind, resulting in lower isosteric heat of sorption (Iglesias \& Chirife, 1976a; Jayendra Kumar et al., 2005). As moisture content further increases, heat of sorption tends to the value of pure water, which indicates that the moisture exists in its free form. The isosteric heat of sorption for coffee fruit was lower than those of pulped and green coffee samples for all values of moisture content. These results agree with those found by Martinez \& Chiralt (1996), who reported that hulling process decreased values of sorption heat of hazelnut, almond and peanut samples. Probably, it was because of enhancement of lipid-lipid interaction that increases the hydrophobicity of cellular components of seeds. Furthermore, because of the low hygroscopicity of the layer that involves pulped coffee, values of isosteric heat of sorption of green and pulped coffees were similar.

The isosteric heat of sorption values for green coffee, pulped coffee and coffee fruit are similar to those encountered by Corrêa et al. (2007), who researched peanut pods, kernels and hulls, and Kaya \& Kahyaoglu (2006), who researched sesame seeds in different processing levels, and lower than values reported by Samapundo et al. (2007), for yellow dent corn. The isosteric heat of sorption for green, pulped and coffee fruits with respect to equilibrium moisture content was adequately described by the power law relationship, presented in Table S6.

To know the magnitude of the heat of sorption at a specific moisture content provides an indication of the state of sorbed water and hence a measure of the physical, chemical and microbiological stability of the food material under given storage conditions. In addition, the variation in heat of sorption with moisture content and magnitude relative to the latent heat of vaporisation of pure water provides valuable data for energy consumption calculations, followed by the design of drying equipments, and an understanding of the extent of water-solid versus water-water interactions (McMinn \& Magee, 2003).

\section{Conclusions}

Experimental results illustrated that equilibrium moisture content $\left(M_{\mathrm{e}}\right)$ increased as temperature decreased, at constant equilibrium water activity. Furthermore, at constant temperature, $M_{\mathrm{e}}$ increased as water activity increased. Coffee fruits, pulped coffee and green coffee have distinct hygroscopicities. The order in the magnitude of equilibrium moisture contents at each water activity values was found as coffee fruits samples had 
higher equilibrium moisture content than samples of pulped and green coffee.

Sorption isotherms of pulped and green coffee had similar values, and coffee fruits presented higher values of equilibrium moisture content at a certain value of relative humidity. Based on statistical parameters and ease of use, the modified Henderson model was the one that best represented the hygroscopicity phenomenon of coffee fruits, pulped coffee and green coffee. Likewise, the ANN model is suitable to represent the experimental data.

The isosteric heat of desorption of all samples, calculated using the Clausius-Clapeyron equation, showed power relationships with moisture content. Coffee fruits had higher isosteric heat of sorption than that pulped and green coffee.

\section{Acknowledgments}

The authors thank to Illy Café for providing the coffee fruits and to FAPEMIG and $\mathrm{CNPq}$ for the funding aid indispensable to accomplish this work.

\section{References}

Aguerre, R., Suarez, C. \& Viollaz, P. (1988). The temperature dependence of isosteric heat of sorption of some cereal grains. International Journal of Food Science and Technology, 23, 141-145.

Al-Muhtaseb, A.H., McMinn, W.A.M. \& Magee, T.R.A. (2004) Water sorption isotherms of starch powders Part 1: mathematical description of experimental data. Journal of Food Engineering, 61, 297-307.

Aviara, N.A., Ajibola, O.O. \& Oni, S.A. (2004). Sorption equilibrium and thermodynamic characteristics of soya bean. Biosystems Engineering, 87, 179-190.

Bala, B.K., Ashraf, M.A., Uddin, M.A. \& Janjai, S. (2005). Experimental and neural network prediction of the performance of the solar tunnel drier for drying of jackfruit bulbs and jackfruit leather. Journal of Food Process Engineering, 28, 552-566.

Barel, M. \& Jacquet, M. (1994). La qualité du café: ses causes, son appréciation, son amélioration. Plantations Recherche Developpement, 1, 5-10.

Brazil. (1992). Regra para análise de sementes, Ministério da Agricultura e Reforma Agrária, Secretaria Nacional de Defesa Agropecuária. 365 p. Brazil: Brasília.

Brunauer, S., Deming, L.S., Deming, W.E. \& Teller, E. (1940). On a theory of the Van der Waals adsorption of gases. Journal of the American Chemical Society, 62, 1723-1732.

Burmester, K. \& Eggers, R. (2010). Heat and mass transfer during the coffee drying process. Journal of Food Engineering, 99, 430-436.

Chen, C. \& Morey, R.V. (1989). Comparison of four EMC/ERH equations. Transactions of the ASAE, 32, 983-990.

Chowdhury, M.M.I., Huda, M.D., Hossain, M.A. \& Hassan, M.S. (2006). Moisture sorption isotherms for mungbean (Vigna radiata L.). Journal of Food Engineering, 74, 462-467.

Corrêa, P.C., Martins, D.S.R. \& Melo, E.C. (1995). Umigrãos: Programa para o cálculo do teor de umidade de equilibrio para os principais produtos agrícolas. 10P. Brazil: Viçosa, MG. Centreinar UFV.

Corrêa, P.C., Goneli, A.L.D., Jaren, C., Ribeiro, D.M. \& Resende, O. (2007). Sorption isotherms and isosteric heat of peanut pods, kernels and hulls. Food Science Technology International, 13, 231-238.
Draper, N.R. \& Smith, H. (1998). Applied Regression Analysis. 736 pp. New York: Weley series in probability and mathematical statistics, John Wiley \& Sons.

FAO (2008). Available from: http://faostat.fao.org. (Accessed on 23 October 2008).

Furmaniak, S., Terzyk, A.P. \& Gauden, P.A. (2007). The general mechanism of water sorption on foodstuffs - Importance of the multitemperature fitting of data and the hierarchy of models. Journal of Food Engineering, 82, 528-535.

Giner, S.A. \& Gely, M.C. (2005). Sorptional parameters of sunflower seeds of use in drying and storage stability studies. Biosystems Engineering, 92, 217-227.

Iglesias, H.A. \& Chirife, J. (1976a). Isosteric heats of water vapour sorption on dehydrated foods. Part II: hysteresis and heat of sorption comparison with BET theory. Lebensmittel Wissenschaft and Technologie, 9, 123-127.

Iglesias, H.A. \& Chirife, J. (1976b). Prediction of effect of temperature on water sorption isotherms of food materials. Journal of Food Technology, 11, 107-113.

Iguaz, A. \& Vírseda, P. (2007). Moisture desorption isotherms of rough rice at high temperatures. Journal of Food Engineering, 79, 794-802.

Janjai, S., Intawee, P. \& Tohsing, K. (2009). Neural network modeling of sorption isotherms of longan (Dimocarpus longan Lour.). Computers and Electronics in Agriculture, 66, 209-214.

Jayas, D.S. \& Mazza, G. (1993). Comparison of five-three parameter equations for the description of adsorption data of oats. Transactions of the ASAE, 36, 119-125.

Jayendra Kumar, A., Singh, R.R.B., Patil, G.R. \& Patel, A.A. (2005). Effect of temperature on moisture desorption isotherms of kheer. LWT - Food Science and Technology, 38, 303-310.

Kaya, S. \& Kahyaoglu, T. (2006). Influence of dehulling and roasting process on the thermodynamics of moisture adsorption in sesame seed. Journal of Food Engineering, 76, 139-147.

Lertworasirikul, S. \& Tipsuwan, Y. (2008). Moisture content and water activity prediction of semi-finished cassava crackers from drying process with artificial neural network. Journal of Food Engineering, 84, 65-74.

Martinez, N.N. \& Chiralt, A. (1996). Influence of roasting on the water sorption isotherms of nuts. Food Science and Technology International, 2, 399-404.

Mazza, G. \& Lemaguer, M. (1980). Dehydration of onion: some theoretical and practical considerations. Journal of Food Technology, 15, 181-194.

McMinn, W.A.M. \& Magee, T.R.A. (2003). Thermodynamic properties of moisture sorption of potato. Journal of Food Engineering, 60, $155-157$.

Mohapatra, D. \& Rao, P.S. (2005). A thin layer drying model of parboiled wheat. Journal of Food Engineering, 66, 513-551.

Mohsenin, N.N. (1986). Physical Properties of Plant and Animal Materials. 841 p. New York: Gordon and Breach Publishers.

Movagharnejad, K. \& Nikzad, M. (2007). Modeling of tomato drying using artificial network. Computers and Electronics in Agriculture, 59, 78-85.

Mulet, A., Garcya-Pascual, P., Sanjuán, N. \& Garcia-Reverter, J. (2002). Equilibrium isotherms and isosteric heats of morel (Morchella esculenta). Journal of Food Engineering, 53, 75-81.

Oliveira, G.H.H., Corrêa, P.C., Araújo, E.F., Valente, D.S.M. \& Botelho, F.M. (2010). Desorption isotherms and thermodynamic properties of sweet corn cultivars (Zea mays L.). International Journal of Food Science and Technology, 45, 546-554.

Özdemir, M. \& Devres, Y.O. (1999). The thin layer drying characteristics of hazelnuts during roasting. Journal of Food Engineering, 42, 225-233.

Pagano, A.M. \& Mascheroni, R.H. (2005). Sorption isotherms for amaranth grains. Journal of Food Engineering, 67, 441-450. 
Palipane, K.B. \& Driscoll, R.H. (1992). Moisture sorption characteristics of inshell macadamia nuts. Journal of Food Engineering, 18, 63-76.

Panchariya, P.C., Popovic, D. \& Sharma, A.L. (2002). Desertion isotherm modeling of black tea using artificial neural networks. Drying Technology, 20, 351-362.

Peng, G., Chen, X., Wu, W. \& Jiang, X. (2007). Modeling of water sorption isotherm for corn starch. Journal of Food Engineering, 80, 562-567.

Pfost, H.B., Mourer, S.G., Chung, D.S. \& Milliken, G.A. (1976). Summarizing and reporting equilibrium moisture data for grains. ASAE Paper No 76-3520. St Joseph, MI: ASAE.

Poonnoy, P., Tansakul, A. \& Chinnan, M. (2007). Artificial neural network modeling for temperature and moisture content prediction in tomato slices undergoing microwave-vacuum drying. Journal of Food Science, 72, 42-47.

Quintero, G.I.P. (1999). Influencia del proceso de beneficio en la calidad del cafe. Cenicafé, 50, 78-88.

Samapundo, S., Devlieghere, F., Meulenaer, B., Atukwase, A., Lamboni, Y. \& Debevere, J.M. (2007). Sorption isotherms and isosteric heats of sorption of whole yellow dent corn. Journal of Food Engineering, 79, 168-175.

Sanchez, E.S., Sanjuan, R., Simal, S. \& Rossello, C. (1997). Calorimetric techniques applied to the determination of isosteric heat of desorption for potato. Journal of Science Food and Agriculture, 74, 57-63.

Thompson, H.L. (1972). Temporary storage of high moisture shelled corn using continuous aeration. Transactions of the ASAE, 15, 333337.

Van den Berg, C. \& Bruin, S. (1981). Water activity and its estimation in food systems. In: L.B. Rockland \& G.F. Stewart (Eds.), Water Activity: Influences on Food Quality. pp. 147-177. New York: Academic Press.

Wang, N. \& Brennan, J.G. (1991). Moisture sorption isotherm characteristics of potato at four temperatures. Journal of Food Engineering, 14, 269-287.

Wilbaux, R. (1961). Le traitement du café. 214 p. Roma: Organización de las naciones para la alimentación y la agricultura.

Yazdani, M., Sazandehchi, P., Azizi, M. \& Ghobadi, P. (2006). Moisture sorption isotherms and isosteric heat for pistachio. European Food Research Technology, 223, 577-584.

\section{Supporting Information}

Additional Supporting Information may be found in the online version of this article:
Figure S1. Flow chart of the wet processing of coffee. Figure S2. Structure of the artificial neural network model of the equilibrium moisture content of coffee.

Figure S3. Residuals plots for Modified Henderson model adjusted by coffee fruit $(\mathrm{O})$, coffee pulped $(\Delta)$ and green coffee $(\square)$.

Figure S4. Equilibrium moisture content values of coffee fruit $(\mathrm{O})$, coffee pulped $(\Delta)$ and green coffee $(\square)$ for temperature of $10{ }^{\circ} \mathrm{C}$ and their isotherms calculated by the Modified Henderson model.

Figure S5. Correlation of neural network predicted values $\left(M_{\text {pre }}\right)$ vs. experimental values $\left(M_{\exp }\right)$ of equilibrium moisture content of coffee.

Figure S6. Isosteric heat of sorption at different moisture contents for coffee fruit $(\mathrm{O})$, coffee pulped $(\Delta)$ and green coffee $(\square)$.

Table S1 Mathematical models used to identify the equilibrium moisture content of products of vegetable origin

Table S2 Estimated parameters and comparison criteria for the equilibrium moisture content models of green coffee

Table S3 Estimated parameters and comparison criteria for the equilibrium moisture content models of coffee pulped

Table S4 Estimated parameters and comparison criteria for the equilibrium moisture content models of coffee fruit

Table S5 Bias and weight values for the ANN layers

Table S6 Equations to estimate the isosteric heat of sorption for green, pulped and coffee fruits and their respective determination coefficient $\left(R^{2}\right)$

Please note: Wiley-Blackwell are not responsible for the content or functionality of any supporting materials supplied by the authors. Any queries (other than missing material) should be directed to the corresponding author for the article. 